\title{
Global capabilities of BeiDou Navigation Satellite System
}

\author{
Jun Lu', Xia Guo ${ }^{2}$ and Chengeng Su ${ }^{1 *} \mathbb{D}$
}

\begin{abstract}
The BeiDou Navigation Satellite System (BDS) has completed the constellation deployment and started to provide global services. After achieving the capabilities of global coverage, global first-class accuracy for Positioning, Navigation and Timing (PNT), global Inter-Satellite Links (ISL) networking, and global featured services, BDS will promote the construction of the comprehensive PNT infrastructure in the new era and play a more active role in international cooperation with other Global Navigation Satellite System (GNSS) providers to better serve humankind and the world.
\end{abstract}

Keywords: BDS, Capabilities, PNT, Performance

BDS is a global navigation system constructed and operated independently by China. As a significant space infrastructure, the BDS provides all-time, all-weather and high-accuracy positioning, navigation and timing services to global users.

In the late 20th century, China started to explore a development path of the satellite navigation system suited to national conditions, and gradually formulated a three-step development plan. The first step is to complete the construction of the BeiDou Navigation Demonstration System (BDS-1) and provide services to the whole country. The second step is to complete the construction of the BeiDou Navigation Satellite (regional) System (BDS-2) and provide services to the Asia-Pacific region by the end of 2012 (Yang et al. 2014). The third step is to complete BDS and provide services around 2020 (China Satellite Navigation Office 2016; Yang et al. 2018, 2019, 2020). With the successful launch of the last Geostationary Earth Orbit (GEO) satellite on 23rd June 2020, BDS has completed the constellation. A total of 55 BDS satellites are currently launched into orbit, and provide more continuous, stable, reliable, positioning, navigation and timing services to global users.

\footnotetext{
*Correspondence: 156687438@qq.com

${ }^{1}$ Beijing Institute of Tracking and Telecommunication Technology, Beijing 100094, China

Full list of author information is available at the end of the article
}

Aiming to be a top-class system, BDS is developed by China and dedicated to the world. As it enters into a new global era, BDS has new capabilities and new responsibilities, such as global coverage, global first-class accuracy for PNT, ISL networking, featured services, and global services.

Currently, the global coverage capacity of the BDS has been further improved, and all the availability of space signals has also reached a world-class level. To be more specific, due to the existence of high-orbit satellites (GEO and IGSO satellites, that is, geostationary and inclined geostationary orbit satellites), the number of visible satellites in the Asia-pacific region is between 7 and 15, and the average amount is about 11 (China Satellite Navigation Office 2019a, b; Yang et al. 2018, 2020).

As for the accuracy, based on international GNSS Monitoring and Assessment System (iGMAS) developed by China, it is found that the measured results of Signal-in-Space Range Error (SISRE) of BDS (China Satellite Navigation Office 2019a, b), Galileo Navigation Satellite System (European Commission 2019), and Global Positioning System (GPS) (National Coordination Office 2019) IIF and III satellites are similar, which are all less than $1 \mathrm{~m}$. For the earlier GPS IIR and IIR-M satellites, the SISRE is worse than that of newer satellites, which is about 1-3 $\mathrm{m}$. The SISRE of GLObal Navigation Satellite 
System (GLONASS) (ROSCOSMOS State Space Corporation 2019) is about $2-6 \mathrm{~m}$.

To provide better services, BDS is actively carrying out compatibility and interoperability work with other GNSS providers. Currently, BDS and GPS have reached a consensus on compatibility and interoperability of B1C/ L1C signals, and that of B2a/L5 is being coordinated. BDS and GLONASS have completed Radio Frequency (RF) compatibility coordination, BDS and Galileo have actively engaged in cooperation and in-depth frequency coordination as well (Update on BeiDou Navigation Satellite System 2019).

GNSS requires a global distribution of ground monitoring stations to observe the full arc of the satellites to support accurate orbit determination. All GPS, GLONASS and Galileo adopt global or large-scale station deployment to meet the requirements of continuous global observation. BDS is, however, mainly based on the domestic stations, which requires global observation and operation support through the ISL. By establishing ISL among BDS satellites, the data transmission among satellites and precise measurement have been realized, as well as orbit measurement accuracy and message update frequency have also be improved. At the same time, it can also reduce the dependence on oversea stations, and effectively reduce the operation management cost. At present, all 30 satellites of BeiDou Navigation Satellite System with global coverage (BDS-3) constellation are equipped with inter-satellite links to complete constellation networking.

According to the official document, The Application Service Architecture of the BDS, the BDS-3 will provide a total of six satellite-based services (China Satellite Navigation Office 2016), including Radio Navigation Satellite Service (RNSS) and featured services. BDS will highly integrate Regional Short Message Communication (RSMC), Global Short Message Communication (GSMC), Satellite Based Augmentation System (SBAS), International Search and Rescue (SAR), Precise Point Positioning (PPP) and other featured services, with more intensive and efficient system functions (Yang et al. 2019, 2020).
Specifically, as The Application Service Architecture of BDS (China Satellite Navigation Office 2019a, b) shows the performance standard of BDS services.

\section{(1) RNSS Performance Standard}

BDS-3 utilizes 3 GEO satellites, 3 Inclined GeoSynchronous Orbit (IGSO) satellites and 24 Medium Earth Orbit (MEO) satellites to provide free RNSS services to global users located on or $1000 \mathrm{~km}$ above the Earth's surface. The main BDS RNSS performance indicators are shown in Table 1.

\section{(2) SBAS Service Performance Standard}

BDS utilizes GEO satellites to provide free single-frequency augmentation and dual-frequency multi-constellation augmentation services in accordance with the International Civil Aviation Organization (ICAO) standards to users in China and surrounding areas, aiming to achieve APV-I and the CAT-I precision approach.

\section{(3) PPP Service Performance Standard}

BDS utilizes GEO satellites to provide users in China and surrounding areas with free precise point positioning services. The main performance indicators are shown in Table 2.

\section{(4) RSMC Service Performance Standard}

BDS utilizes GEO satellites to provide the regional short message communication service to users in China and surrounding areas. The main performance indicators are shown in Table 3.

\section{(5) GSMC Service Performance Standard}

BDS utilizes MEO satellites to provide global short message communication services to authorized users located on or $1000 \mathrm{~km}$ above the Earth's surface. The main performance indicators are shown in Table 4.

Table 1 Main BDS RNSS Performance Indicators

\begin{tabular}{|c|c|c|}
\hline Performance characteristics & & Performance indicators \\
\hline \multirow[t]{3}{*}{ Service accuracy (95\%) } & Positioning accuracy & $\begin{array}{l}\text { Horizontal } \leq 10 \text { m Verti- } \\
\quad \text { cal } \leq 10 \mathrm{~m}\end{array}$ \\
\hline & Timing accuracy & $\leq 20 \mathrm{~ns}$ \\
\hline & Velocity measurement accuracy & $\leq 0.2 \mathrm{~m} / \mathrm{s}$ \\
\hline Service availability & & $\geq 99 \%$ \\
\hline
\end{tabular}


Table 2 Main BDS PPP Service Performance Indicators

\begin{tabular}{|c|c|c|}
\hline \multirow[t]{2}{*}{ Performance characteristics } & \multicolumn{2}{|c|}{ Performance indicators } \\
\hline & Phase I (year 2020) & Phase II (after 2020) \\
\hline Broadcast data rate & $500 \mathrm{bit} / \mathrm{s}$ & \multirow{3}{*}{$\begin{array}{l}\text { It will be extended to enhance multiple global navigation systems, to improve broadcast data } \\
\text { rate, to expand satellite service area according to the situation, and to improve positioning } \\
\text { accuracy and shorten convergence time }\end{array}$} \\
\hline Positioning accuracy (95\%) & $\begin{array}{l}\text { Horizontal } \leq 0.3 \mathrm{~m} \\
\text { Vertical } \leq 0.6 \mathrm{~m}\end{array}$ & \\
\hline Convergency time & $\leq 30 \min$ & \\
\hline
\end{tabular}

Table 3 Main BDS RSMC Service Performance Indicators

\begin{tabular}{|c|c|}
\hline $\begin{array}{l}\text { Performance } \\
\text { characteristics }\end{array}$ & Performance indicators \\
\hline Service success rate & $\geq 95 \%$ \\
\hline Service frequency & $\begin{array}{l}\text { Normally once every } 30 \text { s, maximally once } \\
\text { per second }\end{array}$ \\
\hline Response time & $\leq 1 \mathrm{~s}$ \\
\hline Terminal transmission power & $\leq 3 w$ \\
\hline \multicolumn{2}{|l|}{ Service capacity } \\
\hline Uplink & $12,000,000$ times/h \\
\hline Downlink & $6,000,000$ times/h \\
\hline $\begin{array}{l}\text { Maximum length of a single } \\
\text { message }\end{array}$ & $\begin{array}{l}\text { 14,000 bit (approximately equivalent to } \\
1000 \text { Chinese characters) }\end{array}$ \\
\hline \multicolumn{2}{|l|}{ Positioning accuracy (95\%) } \\
\hline RDSS & Horizontal $\leq 20 \mathrm{~m}$ Vertical $\leq 20 \mathrm{~m}$ \\
\hline CRDSS & Horizontal $\leq 10 \mathrm{~m}$ Vertical $\leq 10 \mathrm{~m}$ \\
\hline Two-way timing accuracy & $\leq 10 \mathrm{~ns}$ \\
\hline $\begin{array}{l}\text { Usage constraints and } \\
\text { remarks }\end{array}$ & $\begin{array}{l}\text { If a user's radial velocity relative to the } \\
\text { satellite is greater than } 1000 \mathrm{~km} / \mathrm{h} \text {, } \\
\text { the adaptive doppler compensation is } \\
\text { required }\end{array}$ \\
\hline
\end{tabular}

Table 4 Main BDS GSMC Service Performance Indicators

\begin{tabular}{|c|c|}
\hline Performance characteristics & Performance indicators \\
\hline Service success rate & $\geq 95 \%$ \\
\hline Response time & Normally better than 1 min \\
\hline Terminal transmission power & $\leq 10 w$ \\
\hline \multicolumn{2}{|l|}{ Service capacity } \\
\hline Uplink & 300,000 times/h \\
\hline Downlink & 200,000 times/h \\
\hline $\begin{array}{l}\text { Maximum length of a single } \\
\text { message }\end{array}$ & $\begin{array}{l}560 \text { bit (approximately equivalent to } 40 \\
\text { Chinese characters) }\end{array}$ \\
\hline Usage constraints and remarks & $\begin{array}{l}\text { A user needs to carry out adaptive Dop- } \\
\text { pler compensation, and after the com- } \\
\text { pensation, the frequency offset of the } \\
\text { uplink signal arriving at the satellite } \\
\text { should be less than } 1000 \mathrm{~Hz}\end{array}$ \\
\hline
\end{tabular}

(6) SAR Service Performance Standard

BDS utilizes MEO satellites to provide free distress warning services in accordance with the
Table 5 Main BDS International SAR Service Performance Indicators

\begin{tabular}{ll}
\hline Performance characteristics & $\begin{array}{l}\text { Performance } \\
\text { indicators }\end{array}$ \\
\hline Detection probability & $\geq 99 \%$ \\
Independent positioning probability & $\geq 98 \%$ \\
Independent positioning accuracy & $\leq 5 \mathrm{~km}$ \\
Ground receiving bit error rate & $\leq 5 \times 10^{-5}$ \\
Availability & $\geq 99.5 \%$ \\
\hline
\end{tabular}

COSPAS-SARSAT standards, to maritime, aviation and land users around the world in conjunction with other search and rescue (SAR) satellite systems. It is capable of confirming the service by using a return link. The main performance indicators are shown in Table 5.

Compared to BDS, GPS, GLONASS, Galileo, Navigation with Indian Constellation (NavIC) and Quasi-Zenith Satellite System (QZSS) are also able to provide various services respectively, which is shown in Table 6.

Besides the above six services, BDS is also available for Ground Augmentation System (GAS) service. It utilizes mobile communication networks or the Internet to provide users within the coverage area of reference station network, with high-precision positioning services at the meter, decimeter, centimeter and millimeter levels. The main performance indicators are shown in Table 7.

2020 is the final year of the constellation deployment of the BDS, as well as the starting point of BDS in the new era. By the end of the year, BDS will have been widely used in many fields such as security, economy, and mass-market (China Satellite Navigation Office 2018). For example, BDS products have entered more than 120 countries and regions in the world. Both traditional and emerging applications are growing. BDS applications in traditional fields such as transportation, agriculture, forestry, marine fisheries, surveying, geographic information, power and energy, disaster monitoring have been developed on a larger scale and its achievements has been also further demonstrated (Betz et al. 2019). In emerging fields such as the industrial internet, Internet of Things, and the Internet of Vehicles, innovative applications such 
Table 6 The Provision of Featured Services for Major Satellite Navigation Systems

\begin{tabular}{lllllll}
\hline Service type & China BDS & USA GPS & Russia GLONASS & EU GALILEO & Japan QZSS & India NavIC \\
\hline RNSS & 0 & 0 & 0 & 0 & 0 & 0 \\
SBAS* & 0 & $\times$ & 0 & $\times$ & $\times$ & $\times$ \\
RSMC & 0 & $\times$ & $\times$ & $\times$ & 0 & 0 \\
GSMC & 0 & $\times$ & 0 & 0 & $\times$ & $\times$ \\
SAR & 0 & 0 & $\times$ & 0 & $\times$ & $\times$ \\
PPP & 0 & $\times$ & & & 0 & $\times$ \\
\hline
\end{tabular}

O: available, $x$ : unavailable

*The USA, the EU and India have independently built WAAS, EGNOS and GAGAN Satellite-Based Augmentation Systems (SBAS), respectively. Russia has incorporated SDCM into GLONASS. In the future, QZSS will also provide SBAS service

Table 7 Main GAS Service Performance Indicators

\begin{tabular}{|c|c|c|c|c|c|}
\hline \multirow{2}{*}{$\begin{array}{l}\text { Performance } \\
\text { characteristics }\end{array}$} & \multicolumn{5}{|l|}{ Performance indicators } \\
\hline & $\begin{array}{l}\text { Single- frequency } \\
\text { ranging augmentation } \\
\text { service }\end{array}$ & $\begin{array}{l}\text { Single } \\
\text { carrier phase } \\
\text { augmentation } \\
\text { service }\end{array}$ & $\begin{array}{l}\text { Dual-frequency carrier } \\
\text { phase augmentation } \\
\text { service }\end{array}$ & $\begin{array}{l}\text { Dual-frequency } \\
\text { carrier phase } \\
\text { augmentation } \\
\text { service (Network } \\
\text { RTK) }\end{array}$ & $\begin{array}{l}\text { BDS/GNSS baseline post- } \\
\text { process with accuracy } \\
\text { at millimeter level }\end{array}$ \\
\hline Target system & BDS & BDS & BDS & BDS/GNSS & BDS/GNSS \\
\hline Positioning accuracy & $\begin{array}{l}\text { Horizontal } \leq 2 \text { m Verti- } \\
\text { cal } \leq 3 \text { m (95\%) }\end{array}$ & $\begin{array}{l}\text { Horizon- } \\
\quad \text { tal } \leq 1.2 \mathrm{~m} \\
\text { Vertical } \leq 2 \mathrm{~m} \\
(95 \%)\end{array}$ & $\begin{array}{l}\text { Horizontal } \leq 0.5 \mathrm{~m} \\
\text { Vertical } \leq 1 \mathrm{~m}(95 \%)\end{array}$ & $\begin{array}{l}\text { Horizontal } \leq 5 \mathrm{~cm} \\
\text { Vertical } \leq 10 \mathrm{~cm} \\
(\mathrm{RMS})\end{array}$ & $\begin{array}{l}\text { Horizontal } \leq 5 \mathrm{~mm}+ \\
\quad 1 \times 10^{-6} \times D \text { Vertical } \\
\leq 10 \mathrm{~mm}+2 \times 10^{-6} \times D \\
\text { (RMS) } \\
\text { D means baseline length } \\
\text { in km }\end{array}$ \\
\hline Initialization time & Seconds & $\leq 20 \mathrm{~min}$ & $\leq 40 \min$ & $\leq 60 \mathrm{~s}$ & - \\
\hline
\end{tabular}

as autonomous driving, parking, and logistics are emerging in an endless stream. By 2035, the construction of a comprehensive spatial-temporal system will provide new supports for domestic and global users (Yang 2016).

The global satellite navigation systems are changing dramatically. The higher-quality and better-improved systems will provide more options for global users. As for BDS, it will play a much more active role in international cooperation with other GNSS providers to serve humankind and the world.

\section{Authors' contributions}

$J \mathrm{~L}$ completed the framework of the article and gave the main ideas, and revised the paper; XG evaluated the data and carried out the draft of the manuscript; CS assisted in data collection and communicated with the editorial office.

\section{Availability of data and materials}

The datasets analyzed during the current study are available in the data repositories of Test and Assessment Research Center of China Satellite Navigation Office (www.csno-tarc.cn).

\section{Competing interests}

The authors declare that they have no competing interests.

\section{Author details}

${ }^{1}$ Beijing Institute of Tracking and Telecommunication Technology, Beijing 100094, China. ${ }^{2}$ National Time Service Center, Chinese Academy of Sciences, Xi'an, China.

Received: 8 July 2020 Accepted: 14 July 2020

Published online: 31 August 2020

\section{References}

Betz, J. W., Lu, M., Morton, Y. T. J., \& Yang, Y. (2019). Introduction to the special issue on the BeiDou navigation system. Navigation, 66, 3-5. https://doi. org/10.1002/navi.293.

China Satellite Navigation Office. (2016). China's BeiDou Navigation Satellite System. http://www.beidou.gov.cn/xt/gfxz/201712/P02017122133386 3515306.pdf. Accessed 16 June 2016.

China Satellite Navigation Office. (2018). Applications of the BeiDou navigation satellite system. http://www.beidou.gov.cn/xt/gfxz/201906/P020190605 488535070471.pdf. Accessed 27 Dec 2016.

China Satellite Navigation Office. (2019a). Development of the BeiDou Navigation Satellite System (Version 4.0). http://www.beidou.gov.cn/xt/ gfxz/201912/P020191227430565455478.pdf. Accessed 27 Dec 2019.

China Satellite Navigation Office. (2019b). The Application Service Architecture of BeiDou Navigation Satellite System (version 1.0). http://www.beido u.gov.cn/xt/gfxz/201912/P020191227333024390305.pdf. Accessed 27 Dec 2019. 
European Commission, European Space Agency. (2019). 2019-galileo programme update. In 14th meeting of the international committee on GNSS, 9 December 2019, Bangalore, India.

National Coordination Office, Program and Policy Update. (2019). 14th Meeting of the International Committee on GNSS, 9 December 2019, Bangalore, India.

ROSCOSMOS State Space Corporation. (2019). GLONASS and SDCM Status and Development. In 14th meeting of the international committee on GNSS, 9 December 2019, Bangalore, India.

Update on BeiDou Navigation Satellite System. (2019). 14th Meeting of the International Committee on GNSS, 9 December 2019, Bangalore, India.

Yang, Y. (2016). Concepts of comprehensive PNT and related key technologies CJ. Acta Geodaetica et Cartographica Sinica, 45(5), 505-510. https://doi. org/10.11947/j.agcs.2016.20160127.

Yang, Y., Gao, W., Guo, S., Mao, Y., \& Yang, Y. (2019). Introduction to BeiDou-3 navigation satellite system. Navigation, 2019, 1-12.
Yang, Y., Li, J., Wang, A., Xu, J., He, H., Guo, H., et al. (2014). Preliminary assessment of the navigation and positioning performance of BeiDou regional navigation satellite system. Science China: Earth Sciences, 57(1), 144-152. https://doi.org/10.1007/s11430-013-4769-0.

Yang, Y., Mao, Y., \& Sun, B. (2020). Basic performance and future developments of BeiDou global navigation satellite system. Satellite Navigation, 1, 1-8. https://doi.org/10.1186/s43020-019-0006-0.

Yang, Y., Xu, Y., Li, J., \& Yang, C. (2018). Progress and performance evaluation of BeiDou global navigation satellite system: Data analysis based on BDS-3 demonstration system. Science China: Earth Sciences, 61 (5), 614-624.

\section{Publisher's Note}

Springer Nature remains neutral with regard to jurisdictional claims in published maps and institutional affiliations.

\section{Submit your manuscript to a SpringerOpen ${ }^{\circ}$ journal and benefit from:}

- Convenient online submission

- Rigorous peer review

- Open access: articles freely available online

- High visibility within the field

Retaining the copyright to your article

Submit your next manuscript at $\boldsymbol{\nabla}$ springeropen.com 